ORIGINAL ARTICLE

\title{
Biochemical Factors associated with Breast C ancer in Bangladeshi Women
}

\author{
DAS Hussain ${ }^{1}$, S A hmed², M Hoque 3 , SMR Rabbi4 ${ }^{4}$ S M asood ${ }^{5}$, T Shafi 6 \\ T Parvin ${ }^{7}$, and HS Chaudhury ${ }^{8}$ \\ ${ }^{1}$ D ept of Biochemistry, Shaheed Monsur Ali Medical College and D haka \\ ${ }^{2}$ Dept of Biochemistry, Popular M edical College, Dhaka \\ ${ }^{3}$ Dept of Biochemistry, Bangabandhu Sheikh M ujib Medical U niversity (BSM MU), D haka \\ ${ }^{4}$ Laser Aesthetics, D hanmondi, D haka; ${ }^{5}$ Dept of Physiology, BSM MU, D haka \\ ${ }^{6}$ D ept of Biochemistry, M edical College for Women and Hospital, D haka \\ ${ }^{7}$ Dept of Cardiology, Bangabandhu Sheikh M ujib M edical University (BSM MU), Dhaka \\ ${ }^{8}$ D ept of Biochemistry \& M olecular Biology, International Medical College, Gazipur
}

\begin{abstract}
Breast Cancer is the commonest maligrancy in woment. A study was carried out in the Department of Biochemistry, Dhaka Medical College to investigate some of the biochemical features that are associated with breast cancer occurring in Bangladeshi women. Thirty diagnosed breast cancer patients and thirty healthy women were selected. A questionnaire was used for collecting information regarding age, family history, physical activity and exercise, BMI, diet, smoking, alcohol abuse, addiction, details of menstrual and obstetric history, breast-feeding, parity, use of contraceptives and HRT. Blood samples were collected and tested for fasting lipid profiles, serum estrogen and progesterone. The study has revealed that high levels of serum total cholesterol $(P<0.05)$, TAG $(P<0.05)$, LDL-C $(P<0.05)$ and low level of serum and HDL-C $(P<0.05)$ were found to be associated with breast cancer. The study further reveals that blood levels of estrogen $(P<0.05)$ and progesterone $(P<0.05)$ were found to be lower than that of the controls.
\end{abstract}

Key words: Breast cancer, Lipid profile, Estrogen, Progesterone

\section{Introduction}

One of the commonest malignant diseases occurring in females is breast cancer. Breast malignancy is an important cause of morbidity and mortality in Bangladeshi females. The incidence of breast cancer had been quite steady during the last several years. Currently ten percent of women in the western population are at risk to develop breast cancer ${ }^{1}$. In Bangladesh the occurrence has been quite low but, now a days, the incidence has been rising at an alarming rate.

In spite of an immense amount of investigations there is still no specific known cause of breast cancer. But it has been observed by many researchers that certain factors have got linkage to breast cancer. A risk factor is anything that increases a person's chances of getting the disease. Different cancers have different risk factors. The National Institute of Clinical Excellence (NICE) classified women into three groups, a moderate risk, a high risk or the risk as the general population. ${ }^{2}$

It has been reported that among the risk factors of breast cancer some are established risk factors and cannot be changed. These include gender, age, genetic predisposition, family history, race, early menarche and late menopause. On the other hand there are some factors that can be modified or changed. These include physical activity and diet, obesity, parity, use of different hormonal preparations 
etc. The chance of getting breast cancer in woman increases, as the woman gets older. Nearly 8 out of 10 breast cancers are found in woman over the age of $50 .{ }^{3}$

Race is also an important factor as it has been reported that white women are more likely to get breast cancer. Women who had their menarche before 12 years of age or who went through menopause after the age of 55 years have increased risk of breast cancer.

Women who are childless or those who have their first child after the age of 30, have also higher risk of breast cancer. The association perhaps reflects either a pregnancy-induced maturation of mammary cells making them less susceptible to carcinogenic transformation, or a long lasting hormonal change or both 4,5 . Having the last child at an older age has also been found to be associated with higher risk of breast cancer ${ }^{6}$.

Biochemical risk factors include increase in blood glucose, increase in serum triglyceride level, decrease in high-density lipoprotein level and increased concentrations of the hormones estrogen and progesterone in blood 7 . Recently a study has been conducted which suggests that higher levels of total cholesterol and triglycerides may play an important role in carcinogenesis and that the elevated plasma LDL-cholesterol, which is more susceptible to oxidation may result in high lipid peroxidation in breast cancer ${ }^{8}$.

It was also found that the use of oral contraceptives was associated with an increase in breast cancer and this increased risk persists for 10 years after stopping the pill. It has also been reported that daily use of hormone replacement therapy (estrogen and progesterone) increases a woman's chances of developing breast cancer by about 25\% if taken for several years. ${ }^{5}$

Woman who took combined HRT also had a higher risk of having breast cancer detected at a more advanced stage and was more likely to have abnormal results on mammograms. The British "M illion W omen study" reported a slightly increased risk of breast cancer among women who took Estrogen Replacement Therapy $(E R T)^{4}$. It has been reported that estrogen and progesterone plays a significant role in breast development. Endogenous estrogen excess or more accurately hormonal imbalance clearly plays an important part in the development of breast cancer. In the postmenopausal women adrenal gland is the main source of estrogen, which may play an important role in the development of breast cancer ${ }^{9}$.

It has been found that functioning ovarian tumors that elaborate estrogens are associated with breast cancer in postmenopausal women. Production of some growth factors, which depend on estrogen are thought to be secreted by human breast cancer cells. Interaction between circulating hormones and hormone receptors on cancer cells and growth factors induced by tumor cells are involved in breast cancer progression. According to recent research, multiple serumbased tumor markers have been described for breast cancer, such as CA 15-3, BR-2.29 or CA27.29, carcinoembryonic antigen, tissue polypeptide antigen ${ }^{10}$. They are used for assessing the prognosis of breast cancer and are of little value in the diagnosis. So these tumor markers are not considered to be risk factors.

\section{M aterials and M ethods}

A cross-sectional laboratory study was planned and carried out during January 2006 to December 2006 in the Department of Biochemistry, Dhaka Medical College, in collaboration with Dept of Biochemistry, Bangabandhu Sheikh M ujib M edical U niversity (BSM M U ), D elta M edical Center, Breast Center Dhanmondi and National Institute of Cancer Research \& H ospital, Dhaka.

A questionnaire was used to collect information regarding age, family history, physical activity and exercise, the height and weight of individuals to calculate BMI. Biochemical profiles were measured. Participants enrolled in this study were asked for details regarding their lifestyle oriented physical activity. 
Details on their menstrual history were noted and the age of their menarche, menstrual periods, last menstrual periods and age of menopause were all recorded. Details about breast-feeding were included in the study. M arital status and age when the study subject first got pregnant and the number of issues was all explored. Females were asked about the method they used for contraception. They were asked specifically whether they used intrauterine contraceptive device or implants or deports. Post-menopausal study subjects were asked about taking estrogen and progesterone replacements. All these data were entered and analyzed by Statistical Package for Social Sciences (SPSS)-version 11.5.

For biochemical risk factors samples were collected and preserved for assessing lipid profiles and serum hormonal levels. Collection and preservation of samples were done as per standard methods. Prior to sample collection all the subjects were cordially requested to remain on a 12 hour fast from 8 pm to 8 am next morning. At the end of 12 hour fasting $5 \mathrm{ml}$ of blood was collected from the antecubital vein of each study subject after maintaining all aseptic precautions and immediately then transferred to a dry clean test tube and allowed to clot. Then the sample was centrifuged and serum was collected in a microcentrifuge tube, which was appropriately labelled and preserved at $-20^{\circ} \mathrm{C}$. A fter collection of all samples, serum was used for the measurement of lipid profile and hormones.

\section{Laboratory M ethods}

- Estimation of serum estrogen and progesterone was assayed by Microparticle Enzyme Immunoassay $(\mathrm{MEIA})^{11,12}$

- Estimation of serum total cholesterol concentration by enzymatic colorimetric CHOD -PA P method 15 .

- Estimation of serum HDL -C concentrationwas done by enzymatic colorimetric Phosphotungstic acid/ $/ \mathrm{M} \mathrm{gCl}_{2}$ method 16 .

- Estimation of serum triglyceride concentration by enzymatic colorimetric GPO-PAP method ${ }^{17}$.

- Calculation of serum LDL-C concentration using F riedwald's formula 18

- Estimation of blood glucose by GOD method.
The quantitative variables were expressed as mean \pm SD or median (range) as appropriate. $P$ value $<0.05$ was taken as level of significance. Chi square test was done to see the association among different risk factors of breast cancer. To compare statistical differences between two groups unpaired Student's ' $t$ ' test was done.

\section{R esults}

A total of 60 subjects, all of which were females, were included in the study. The subjects were divided into two groups. In Group I thirty breast cancer patients were selected while in Group II, thirty healthy women were taken as control.

Concentrations of lipid profile (TC, TG, HDL $C, L D L-C)$ in different groups were expressed in $\mathrm{mg} / \mathrm{dL}$. Serum estrogen and progesterone was expressed in $\mathrm{pg} / \mathrm{ml}$ and $\mathrm{nmol} / \mathrm{L}$ respectively. Serum lipid profile levels in different groups are presented in Table I.

Serum levels of TC in mg/dL, HDL-C mg/dL, LDL-C $\mathrm{mg} / \mathrm{dL}$, and $T G \mathrm{mg} / \mathrm{dL}$, were $205.0 \pm 14.0,29.0 \pm 6.0,129.0 \pm 5.0,193.0 \pm$ 15.0 in cases and $190.0 \pm 10.0,34.0 \pm 3.0$, $109.0 \pm 9.0,158.0 \pm 12.0$ in controls respectively.

Table-I: Serum lipid profiles in study subjects

\begin{tabular}{llll}
\hline $\begin{array}{l}\text { Parameter } \\
m \pm S D \text { in } m g / d l\end{array}$ & $\begin{array}{c}\text { Group I } \\
n=30\end{array}$ & $\begin{array}{c}\text { Group II } \\
n=30\end{array}$ & $P$ \\
\hline TC & $205.0 \pm 14.0$ & $190.0 \pm 10.0$ & $<.0 .05$ \\
HDL $-C$ & $29.0 \pm 6.0$ & $34.0 \pm 3.0$ & $<.0 .05$ \\
LDL $-C$ & $129.0 \pm 5.0$ & $109.0 \pm 9.0$ & $<.0 .05$ \\
TG & $193.0 \pm 15.0$ & $158.0 \pm 12.0$ & $<.0 .05$ \\
\hline
\end{tabular}

The mean \pm SD of estrogen was $39 \pm 12 \mathrm{pg} / \mathrm{ml}$ and progesterone was $0.75 \pm 0.3 \mathrm{nmol} / \mathrm{L}$ in cases and in controls estrogen was $65 \pm 16 \mathrm{pg} / \mathrm{ml}$ and progesterone was $2 \pm 0.3 \mathrm{nmol} / \mathrm{L}$ (Table-II). 
Biochemical Factors associated with Breast Cancer

Table II: Serum Estrogen and Progesterone Levels in study subjects

\begin{tabular}{lccc}
\hline & Group -I & Group - I & \\
\hline Parameter & $\mathrm{n}=30$ & $\mathrm{n}=30$ & $\mathrm{p}$ \\
$\mathrm{m} \pm \mathrm{SD}$ & $\mathrm{m} \pm \mathrm{SD}$ & \\
$\begin{array}{l}\text { Estrogen } \\
(\mathrm{pg} / \mathrm{ml})\end{array}$ & $39 \pm 12$ & $65 \pm 16$ & $<0.05$ \\
$\begin{array}{l}\text { Progesterone } \\
(\mathrm{nmol} / \mathrm{L})\end{array}$ & $0.75 \pm 0.3$ & $2 \pm 0.3$ & $<0.05$ \\
\hline
\end{tabular}

Results are expressed as mean \pm SD

\section{Discussion}

In the present cross-sectional study an association between risk factors and breast cancer has been studied in Bangladeshi breast cancer female patients. Among the biochemical parameters, lipid profile and serum estrogen and progesterone were studied.

In the present study a significant association was found between the use of Oral Contraceptive Pill (OCP) and breast cancer. There seems to have a lot of controversy regarding this association. A number of studies showed no increased risk, instead showed protective role against breast malignancy ${ }^{19}$. On the other hand, some studies showed that the OCP do not increase the risk for breast cancer, but they increase the incidence of benign breast diseases.

In the present study a significant difference in lipid profiles was found between cases and control. Serum total cholesterol and triglycerides were found to be elevated in cases. Furthermore, a rise in low-density lipoprotein and decreased serum levels of high-density lipoprotein were observed. These findings were consistent with that of other studies ${ }^{7}$.

Recent studies suggest that higher levels of total cholesterol and TG may play an important role in carcinogenesis, and that elevated plasma LDLconcentration that is more susceptible to oxidation, may result in higher lipid peroxidation in breast cancer patients. The studies reveal that the decreased concentration of HDL -C might cause the reactive oxygen metabolites to remain unopposed8. In a separate study in Norway, it was reported that low serum high-density lipoprotein cholesterol (HDL-C) was an important component of the metabolic syndrome, and has recently been related to breast cancer risk in overweight and obese women ${ }^{21}$.

Recent studies suggest that higher levels of total cholesterol and TG may play an important role in carcinogenesis, and that elevated plasma LDL-concentration that is more susceptible to oxidation, may result in higher lipid peroxidation in breast cancer patients. The studies reveal that the decreased concentration of HDL-C might cause the reactive oxygen metabolites to remain unopposed ${ }^{8}$. In a separate study in Norway, it was reported that low serum high-density lipoprotein cholesterol (HDL-C) was an important component of the metabolic syndrome, and has recently been related to breast cancer risk in overweight and obese women ${ }^{21}$.

In the present study although serum levels of estrogen and progesterone were found low in cases, this could probably be due to the failure of proper matching between the cases and the controls with respect to their different phases of menstrual cycle during the measurements of blood hormones. Moreover, the sample size was small.

The present study suggests that high levels of serum total cholesterol, TAG, LDL-C and low level of serum and HDL-C are to be associated with breast cancer. It also indicates that breast cancer patients also have a lower level of both estrogen and progesterone as compared to controls. 
62 Bangladesh J M ed Biochem; 6(2)

\section{R eferences}

1. Harris, JR et al Breast Cancer, NEMJ 1992; 327: 319.

2. National Cancer Institute's (NCI) Surveillance, Epidemiology, and End Results (SEER) Program has published its SEER Cancer Statistics Review 1975-2003.

3. Walker AR. Breast cancer-can risks really lessened? Eur J Cancer Prev 2000; 9: 223-229.

4. Chen WY et al. Use of postmenopausal hormones, alcohol and risk for invasive breast cancer. Ann Intern M ed 2002; 137: 798-804.

5. Chie WC. Hsieh C. Newcomb PA. Age at any full term pregnancy \& breast cancer risk, Am J Epiodemiol 2000: 1. 715-22.

6. MacM ahon $B$, Cole $P$, lin $T M$, et als first birth and breast cancer risk, Bull World Heah Organ 1970; 43: 209-21.

7. McTiernan A. A ssociations between energy balance and body mass index and risk of breast carcinoma in women from diverse racial and ethnic backgrounds in US. Cancer 2000; 8: 1248-1255.

8. Gibanananda Ray and Syed A. Hussain, Role of Lipids, Lipoproteins and vitamins in women with breast cancer, clinical Biochemistry 2001; 34 (1): 71-76.

9. Bray GA, The Underlying basis for Obesity: Relationship to Cancer, J. Nutrition, 2002; 132: 3451-3455.

10. Duffy, Breast Cancer Prognosis predicted with serum tumour marker, May 6, 2006, NewsRx.com. http://www. newsRx.com/article ID = 315797

11. Carr BR. Disorders of the Ovary and Female Reproductive Tract. In: Wilson JD, Foster DW, Editors. William Textbook of Endocrinology. Philadelphia; WB Saunders Co., 1992; 733-98.
DAS Hussain, S A hmed, M Hoque, SM R Rabbi et al

12. Speroff $L$, Glass RH, Kase NG. The Endocrinology of Pregnancy. In Mitchell C, Editor, Clinical Gynecologic Endocrinology and Infertility, 5th $\mathrm{Ed}$. Baltimore; Williams and Wilkins 1994: 183-230.

13. A braham GE et.al, Simultaneous Radioimmunoassay of Plasma FSH, LH, Progesterone, 17-Hydroxyprogesterone and Estradiol -17 beta during the Menstrual Cycle. J Clin Endocrinol Metab 1972; 34-2: 312-318.

14. Whitley RJ et al., In Tietz Textbook of Clinical Chemistry, 1994; 1866-867.

15. Allian et al., 1974; Cited by Gowland E; Lipid and Lipoprotein; In Varley's Practical Clinical Biochemistry, 6th Edition, 1996; Goenlock AH, M cM urray JR, M CLauchlan DM ; Butterworth Heinmann L td., UK.

16. Burstein et al.,1970 jn.nutrition.org / content /129/12/2177. long

17. Buccolo and David 1973; cited by Gowland E; Lipid and lipoprotein; V arley's Practical Clinical Biochemistry,6th Edition, 1996; Gowenlock AH, M cMurray JR, M CL auchlanD M; Butterworth Heinemann Ltd. UK; 452-476.

18. Lebow MA. The pill and the press: reporting risk. Obstet Gynecol 1999; 93: 453-456.

19. Montazeri, A et al., The Role of depression in the development of breast cancer: analysis of registry data from a single institute. A sian Pacific J Cancer Prev 2004: 3: 316-319.

20. Furberg AS Thune I. M etabolic abnormalities (hypertension, hyperglycemia and overweight), Lifestyle (high energy intake and physical activity) and endometrial cancer risk in a Norwegian cohort. Int J Cancer 2003; 104: 669-76. 